\title{
Profile of Implementing Google Classroom As A SMK Physics Learning Media
}

\author{
Intan Fatmawati ${ }^{* 1)}$, Dwi Sulisworo ${ }^{2)}$ \\ ${ }^{1,2)}$ Masters in physics education, Ahmad Dahlan University \\ e-mail: intanfatmawati82@gmail.com \\ sulisworo@gmail.com
}

\begin{abstract}
Learning management system (LMS) is a learning solution in the midst of the Covid-19 pandemic situation. In addition, the LMS learning media is also a medium that supports education in the demands of technological development 4.0. LMS is an online-based application designed to assist the learning process with creative and innovative material designs. LMS has many types, this time the researcher uses google classroom as a learning medium. The purpose of this research was to profile the application of physics learning using google classroom media at SMK Bodronoyo Jiwan, Madiun. The sample used was class X students majoring in APHP at SMK Bodronoyo Jiwan, Madiun. This research method is a descriptive qualitative data analysis model using the Technology Acceptance Model (TAM). The results of this research explain that the learning applied in class X APHP using google classroom gets a very good response. Obtaining this data states that on average students respond very satisfied, this is explained in 5 aspects, namely ease of access, perceived usefulness, communication and interaction, delivery of instructions, and student satisfaction on the application of Google Classroom in teaching and learning activities.
\end{abstract}

Keywords: Covid-19, LMS, google classroom, physics learning media, TAM. 


\title{
Profil Penerapan Google Classroom Sebagai Media Pembelajaran Fisika SMK
}

\author{
Intan Fatmawati ${ }^{* 1)}$, Dwi Sulisworo ${ }^{2)}$ \\ ${ }^{1,2)}$ Magister Pendidikan Fisika, Universitas Ahmad Dahlan
}

\begin{abstract}
Abstrak
Learning management system (LMS) menjadi solusi pembelajaran di tengah situasi pandemi Covid-19. Selain itu media pembelajaran LMS juga menjadi media yang mendukung pendidikan dalam tuntutan perkembangan teknologi 4.0. LMS merupakan aplikasi berbasis online yang didesain untuk membantu proses pembelajaran dengan rancangan materi yang kreatif dan inovatif. LMS memiliki banyak jenisnya, pada kali ini peneliti menggunakan google classroom sebagai media pembelajaran. Tujuan penelitian ini untuk memprofilkan penerapan pembelajaran fisika dengan menggunakan media google classroom di SMK Bodronoyo Jiwan, Madiun. Sampel yang digunakan yaitu siswa kelas X jurusan APHP di SMK Bodronoyo Jiwan, Madiun. Metode penelitian ini yaitu deskriptif kualitatif dengan model analisis data menggunakan Technology Acceptance Model (TAM). Hasil penelitian ini menerangkan bahwa pembelajaran yang diterapkan di kelas X APHP menggunakan google classroom memperoleh respon sangat baik. Perolehan data ini menyatakan bahwa rata-rata siswa memberikan respon sangat puas, hal ini dijelaskan pada 5 aspek yaitu kemudahan akses, dipersepsi kegunaan, komunikasi dan interaksi, penyampaian instruksi dan kepuasan siswa pada penerapan Google Classroom dalam kegiatan belajar mengajar.
\end{abstract}

Kata kunci: Covid-19, google classroom, LMS, media pembelajaran fisika, TAM.

\section{Pendahuluan}

Pandemi COVID-19 telah mempengaruhi berbagai macam aspek kehidupan salah satunya dalam bidang pendidikan. Kondisi tersebut berpengaruh terhadap keberlangsungan proses pembelajaran, dimana pembelajaran biasanya dilakukan secara tatap muka, kini harus dilaksanakan secara jarak jauh. Kondisi ini tidak menghambat seorang pendidik untuk melaksanakan proses pembelajaran, pendidik harus kreatif dalam mengolah media pembelajaran dengan memanfaatkan teknologi yang ada. Perlunya memanfaatkan dan meningkatkan strategistrategi pembelajaran dengan menggunakan perkembangan teknologi sebagai strategi dalam pembelajaran (Ahmadi, 2018; Gilakjani, 2017; Pratiwi et al., 2019).

Media pembelajaran menjadi komponen utama dalam membantu proses pembelajaran, sebagaimana yang diketahui bahwa media pembelajaran didefenisikan sebagai alat yang digunakan untuk membantu proses pembelajaran (Wijaya et al., 2017). Media berfungsi sebagai alat yang membantu mempermudah penyampaian materi ke siswa, baik melalui tulisan, pengamatan video, ataupun melewati gambar (Daryanto, 2010). Namun seiring perkembangan zaman, dunia pendidikan harus menyesuaikan diri dalam perkembangannya. Untuk melengkapi pembelajaran yang berbasis teknologi, Learning Management System (LMS) mempunyai peran penting dalam menopang keberhasilan pembelajaran (Chung et al., 2013).

LMS merupakan aplikasi perangkat lunak yang didesain untuk membantu proses pengajaran dan pembelajaran, sistem ini menyarankan cara untuk meningkatkan efisiensi pengajaran (Coates et al., 2005; Machado \& Tao, 2007; Watson \& Watson, 2007). Pembelajaran berbasis Learning Menagement System (LMS) ini berperan penting dalam menjawab tantangan zaman terutama dalam peningkatan penggunakan teknologi, siswa dilatih untuk melek terhadap teknologi, melatih berfikir kritis, kreatif, belajar mandiri dan masih banyak lagi yang lainnya, penggunaan Learning Menagement System (LMS) bisa dilakukan secara fleksibel, bisa dilakukan dimanapun dan kapanpun (Hamuy \& Galaz, 2010; Mtebe, 2015; Uys, 2010). Keberhasilan dalam suatu pembelajaran 
yang berbasis virtual sangat dipengaruhi dari keterampilan, inovasi dan kemampuan dari seorang instruksi (Emelyanova \& Voronina, 2020; Webster \& Hackley, 1997). Daya tarik, kualitas sistem, dan yang pendukung lainnya menjadi hal yang perlu diperhatikan dalam pengembangan pembelajaran berbasis Learning Menagement System (LMS).

LMS (Learning Menagement System) juga mempunyai keunggulan dan banyak manfaat dalam proses pembelajaran, seperti mempermudah pembelajaran, memberikan pembelajaran yang lebih unik dan menyenangkan dengan sajian materi yang diberikan dan diarahkan oleh gurunya, dan sebagainya (Wang et al., 2012). Dalam pemilihan LMS yang tidak memberatkan pengguna perlu mempertimbangkan beberapa hal seperti kuota internet, kapasitas aplikasi yang memakan banyak ruang, dan kemudahan dalam mengakses. Hal ini sangat perlu dipertimbangkan dalam mendukung suatu pembelajaran yang menyenangkan. Komponen komponen yang disebutkan itu contohnya seperti aplikasi google classroom, google meet, e-learning sebagai alat pembelajaran pada LMS (Octaberlina \& Muslimin, 2020).

Google classroom merupakan aplikasi web yang dikembangkan untuk membuat forum didunia maya serta menyederhanakan segala proses dalam tahapan pembelajaran, seperti pembuatan materi, pemberian nilai (Murtikusuma et al., 2019; Okmawati, 2020; Shaharanee et al., 2016; Syakur et al., 2020). Google classroom sangat membantu dalam mempermudah proses pembelajaran jarak jauh, selain itu google classroom secara kegunaan juga sangat mudah diakses dan memiliki fiturfitur yang mudah diakses. Fitur-fitur yang ada pada google classroom seperti penilaian pada tugas, menyediakan ruang untuk mengirim tugas yang telah dikumpulkan (Shahroom \& Hussin, 2018). Namun dibalik kemudahan dari google classroom, terdapat tantangan khusus pada guru, pertama dari segi menyakinkan kepeserta didik bahwa penggunaan google classroom itu mudah, kemudian kedua dari segi materi guru harus mempersiapkan materi yang menarik yang mampu memikat peserta didik untuk belajar secara mandiri. Google classroom untuk kegunaan sudah jelas bahwa media pembelajaran ini sangat efektif dan berpengaruh positif bagi proses pembelajaran, dan juga tidak akan memberatkan peserta didik, untuk itu peneliti menggunakan media ini sebagai solusi dalam pembelajaran daring dimusim pandemi Covid-19 dan sebagai pendukung kemajuan teknologi abad 4.0.

Melalui penelitian ini, peneliti bermaksud untuk memprofilkan keefektifan penggunaan google classroom dengan analisis Technology Acceptance Model (TAM) dengan tujuan mengukur tingkat pemahaman terhadap media pembelajaran yang diterapkan.

\section{Metode Penelitian}

Metode yang digunakan yaitu deskriptif kualitatif dengan model TAM (Technology Acceptance Model). Model ini adalah model yang mengukur tingkat keberpengaruhan dalam penerimaan di bidang teknologi serta model yang paling banyak digunakan untuk menjelaskan pendapat secara luas tentang penerimaan teknologi secara pribadi (Lee et al., 2009; Legris et al., 2003). Teknik pengumpulan data dilakukan dengan cara penyebaran angket, kemudian dianalisis dengan cara deskriptif kualitatif. Sasaran penelitian ini adalah siswa SMK Bodronoyo Kelas $\mathrm{X}$ Jurusan APHP. Pelaksanaan penelitian dimulai pada bulan Oktober 2020 di SMK Bodronoyo, Jiwan, Madiun. Pengukuran respon menggunakan 5 aspek dengan 14 pertanyaan dan sistem pengukurannya menggunakan skala 1 tidak setuju sampai dengan skala 5 sangat setuju. Untuk angket diadaptasi dari (Shaharanee et al., 2016).

\section{Hasil dan Pembahasan}

Perlunya mengetahui tingkat keberhasilan dari pelaksanaan proses pengajaran dengan media pembelajaran yang telah diterapkan. Hasil dari pengukuran keefektifan media pembelajaran yang diterapkan kepada siswa SMK Bodronoyo kelas X APHP diukur menggunakan angket yang diadaptasi dari (Shaharanee et al., 2016). Hasil dapat dijelaskan pada Tabel 1.

Berdasarkan Tabel 1, aspek mudah menunjukkan skor di atas rata-rata dengan mean tertinggi mengirimkan komponen tugas dengan mean 4,93. Responden sangat setuju dengan pengenalan google classroom di kelas, 
Tabel 1. Rata-rata respon siswa dalam akses kemudahan

\begin{tabular}{clc}
\hline Aspek & \multicolumn{1}{c}{ Pertanyaan } & $\begin{array}{c}\text { Skor Rata- } \\
\text { rata }\end{array}$ \\
\hline & $\begin{array}{l}\text { Masuk ke google } \\
\text { classroom }\end{array}$ & 4,00 \\
Akses & Mengakses Materi & 4,43 \\
Mudah & $\begin{array}{l}\text { Menerima dan } \\
\text { Mengirim Tugas }\end{array}$ & 4,93 \\
& $\begin{array}{l}\text { Mudah untuk } \\
\text { memahami system }\end{array}$ & 4,07 \\
\hline
\end{tabular}

mereka membuat proses mengirimkan tugas dengan lebih mudah. Respon sama yang diterima pada saat menerapkan google classroom sebagai media pembelajaran di kelas XII OTKP SMKN 1 Lamongan menunjukkan respon sangat positif terhadap kemudahan penggunaan (Pratiwi \& Trisnawati, 2021). Selanjutnya, nilai rata-rata terendah ada pada aspek masuk ke google classroom yaitu 4,00. Meskipun terendah, tapi tidak menghambat dari jalannya pembelajaran menggunakan google classroom.

Tabel 2. Rata-rata respon siswa pada dipersepsi kegunaan

\begin{tabular}{clc}
\hline Aspek & Pertanyaan & $\begin{array}{c}\text { Skor } \\
\text { Rata- } \\
\text { rata }\end{array}$ \\
\hline & $\begin{array}{l}\text { Google classroom } \\
\text { membantu dalam } \\
\text { pembelajaran }\end{array}$ & 4,00 \\
& $\begin{array}{l}\text { Google classroom } \\
\text { sangat bagus } \\
\text { sebagai media } \\
\text { interaksi }\end{array}$ & 2,93 \\
Kegunaan & \\
& $\begin{array}{l}\text { Fitur penilaian } \\
\text { didalamnya } \\
\text { membantu dalam } \\
\text { memantau kinerja } \\
\text { dan pemahaman }\end{array}$ \\
\hline
\end{tabular}

Aspek ke 2 dipersepsi kegunaan skor tertinggi rata-rata 4,50. Responden sepakat bahwa fitur yang disediakan pada penilaian membuat responden memantau kinerja siswa. Sealur dengan penelitian (Yolandari et al., 2020) bahwa google classroom memiliki penilaian yang sangat baik yaitu 0,00 yang nilainya lebih kecil dari probalilitasnya sebesar 0,5 . Hal ini menunjukkan bahwa manfaat yang diberikan didukung dari pemahamannya pada penggunaan google classroom. Selanjutnya nilai rata-rata terendah masuk ke komponen google classroom sangat bagus sebagai media interaksi dengan nilai rata-rata 2,93 sebagaimana Tabel 2. Hasil ini menunjukkan bahwa Responden tidak setuju bahwa media interaksi utama ada pada google classroom, hal ini dikarenakan responden yang kurang sering membuka aplikasi google classroom, responden lebih sering mengguna-kan media interaksi menggunakan aplikasi Whatsapp.

Tabel 3. Rata-rata respon siswa pada komunikasi dan interaksi

\begin{tabular}{clc}
\hline Aspek & \multicolumn{1}{c}{ Pertanyaan } & $\begin{array}{c}\text { Skor } \\
\text { Rata- } \\
\text { rata }\end{array}$ \\
\hline & $\begin{array}{l}\text { Saya merasa } \\
\text { nyaman untuk } \\
\text { berinteraksi } \\
\text { menggunakan } \\
\text { media ini }\end{array}$ & 2,86 \\
& Guru membantu & 4,00 \\
Komunikasi & $\begin{array}{l}\text { mengarahkan jika } \\
\text { dan interaksi } \\
\text { saya merasa } \\
\text { kesulitan dalam } \\
\text { mengakses } \\
\text { sesuatu hal yang } \\
\text { berhubungan } \\
\text { dengan google } \\
\text { classroom }\end{array}$ \\
\hline
\end{tabular}

Aspek ke 3 komunikasi dan interaksi nilai tertinggi memperoleh rata-rata 4,00 pada Tabel 3 , guru sangat membantu responden dalam mengarah-kan pembelajaran menggunakan google classroom. Artinya penggunaan google classroom sebagai media pembelajaran sangat efektif untuk digunakan. Sealur dengan (Syakur et al., 2020) bahwa google classroom sangat membantu dan efektif digunakan dalam proses pembelajaran. Namun disini google classroom belum menjadi media interaksi utama, penjelasan ini memperoleh nilai rata- 
rata 2,86 dengan nilai terendah pada aspek ke 3 , meskipun terendah bukan berarti responden tidak setuju, perlunya pembiasaan agar responden menjadi terbiasa dan proses interaksi dapat berjalan aktif dan efektif.

Tabel 4. Rata-rata respon siswa dalam melihat petunjuk pengiriman

\begin{tabular}{clc}
\hline Aspek & \multicolumn{1}{c}{ Pertanyaan } & $\begin{array}{c}\text { Skor } \\
\text { Rata- } \\
\text { rata }\end{array}$ \\
\hline & $\begin{array}{l}\text { Guru memberikan } \\
\text { instruksi yang jelas } \\
\text { dalam kursus }\end{array}$ & 4,00 \\
& $\begin{array}{l}\text { kegiatan } \\
\text { pembelajaran }\end{array}$ & \\
Melihat & Petunjuk & Guru memberikan \\
Pengiriman & 4,29 \\
& $\begin{array}{l}\text { tanggapan baik } \\
\text { dalam memperjelas } \\
\text { materi untuk } \\
\text { mempermudah } \\
\text { pemahaman saya }\end{array}$ \\
\hline
\end{tabular}

Aspek ke 4 pada Tabel 4 melihat petunjuk pengiriman memperoleh mean tertinggi pada komponen Guru memberikan tanggapan baik dalam memperjelas materi untuk mempermudah pemahaman yaitu sebesar 4,29. Responden sangat setuju bahwa tanggapan guru sangat membantu mempermudah pemahaman responden. Selanjutnya, nilai ratarata terendah yaitu 4,00. Ini menunjukkan responden sangat setuju bahwa dipengertian penyampaian instruksi harus memberikan penjelasan yang jelas terkait petunjuk tentang cara berpartisipasi dalam pembelajaran kursus kegiatan. Hal ini sejalan dengan (Shaharanee et al., 2016) bahwa rata-rata penilaian 4,42 responden setuju dengan penyampaian pendidik dalam menginstruksikan suatu perintah.

Aspek ke 5 kepuasan siswa memperoleh nilai mean tertinggi 4,71 sebagaimana pada Tabel 5. Responden sangat setuju jika google classroom memotivasi dalam pembelajaran dan mean terendah diperoleh nilai 4,00 dengan menanggapi bahwa responden setuju terhadap rekomendasi pembelajaran menggunakan google classroom kepada orang lain. Selaras dengan penelitian (Shaharanee et al., 2016) bahwa pembelajaran yang menggunakan google classroom sangat direkomendasikan untuk digunakan pada mata pelajaran dan di sekolah lainnya.

Tabel 5. Rata-rata respon siswa pada aspek kepuasan

\begin{tabular}{clc}
\hline Aspek & \multicolumn{1}{c}{ Pertanyaan } & $\begin{array}{c}\text { Skor } \\
\text { Rata- } \\
\text { rata }\end{array}$ \\
\hline \multirow{2}{*}{$\begin{array}{l}\text { Google classroom } \\
\text { adalah pilihan pertama } \\
\text { saya dalam belajar } \\
\text { aktif dibandingkan } \\
\text { dengan metode lainnya }\end{array}$} & 3,71 \\
& $\begin{array}{l}\text { Google classroom } \\
\text { memotivasi saya untuk } \\
\text { belajar }\end{array}$ & 4,71 \\
& $\begin{array}{l}\text { Saya } \\
\text { merekomendasikan } \\
\text { metode pembelajaran } \\
\text { ini untuk diterapkan } \\
\text { pada orang lain. }\end{array}$ \\
\hline
\end{tabular}

Google classroom sebagai media pembelajaran yang efektif tentunya sangat berpengaruh positif terhadap kemajuan peserta didik, hal ini diperkuat dengan pernyataan bahwa pembelajaran menggunakan google classroom atau yang berbasis TI sangat efektif digunakan dan memiliki pengaruh positif dalam membantu menfasilitasi guru dan siswa untuk melakukan proses pembelajaran (Etika et al., 2020; Syakur et al., 2020).

\section{Kesimpulan}

Hasil data dan penjelasan yang telah dijabarkan disimpulkan bahwa secara keseluruhan siswa merasa sangat puas terhadap pembelajaran berbasis google classroom, dengan begitu pembelajaran ini sangat efektif digunakan sebagai alat dalam pembelajaran dan sangat membantu dalam proses belajar mengajar.

Setelah mengetahui hasil, maka pendidik/ guru dapat memanfaatkan google classroom sebagai media pembelajaran yang dapat diajarkan dalam pembelajaran. Diharapkan dengan diterapkannya media ini dapat membantu meningkatkan hasil belajar serta pemahaman pada siswa. 


\section{Daftar Pustaka}

Ahmadi, M. R. (2018). The use of technology in english language learning: a literature review. International Journal of Research in English Education (IJREE), 3(2), 115125.

Chung, C. H., Pasquini, L. A., \& Koh, C. E. (2013). Web-based learning management system considerations for Higher education. Learning and Performance Quarterly, 1(4), 24-37.

Coates, H., James, R., \& Baldwin, G. (2005). A critical examination of the effects of learning management systems on university teaching and learning. Tertiary Education and Management, 11(1), 1936.

Daryanto, D. (2010). Media pembelajaran peranannya sangat penting dalam mencapai tujuan pembelajaran. Gava Media.

Emelyanova, N., \& Voronina, E. (2020). Introducing a learning management system at a Russian university: students' and teachers' perceptions. International Review of Research in Open and Distributed Learning, 15(1), 1-19.

Gilakjani, A. P. (2017). A Review of the literature on the integration of technology into the learning and teaching of english language skills. International Journal of English Linguistics, 7(5), 95.

Hamuy, E., \& Galaz, M. (2010). Information versus communication in course management system participation. Computers and Education, 54(1), 169177.

Lee, B. C., Yoon, J. O., \& Lee, I. (2009). Learners' acceptance of e-learning in South Korea: theories and results. Computers and Education, 53(4), 13201329.

Legris, P., Ingham, J., \& Collerette, P. (2003). Why do people use information technology? A critical review of the technology acceptance model. Information and Management, 40(3), 191-204.

Machado, M., \& Tao, E. (2007). Machado2007.Pdf. December 2006, 712.

Mtebe, J. S. (2015). Learning management system success: increasing learning management system usage in higher education in sub-Saharan Africa. International Journal of Education and Development using Information and Communication Technology, 11(2), 5164.

Murtikusuma, R. P., Hobri, Fatahillah, A., Hussen, S., Prasetyo, R. R., \& Alfarisi, M. A. (2019). Development of blended learning based on google classroom with osing culture theme in mathematics learning. Journal of Physics: Conference Series, 1165(1), 1-8.

Octaberlina, L. R., \& Muslimin, A. I. (2020). Efl students perspective towards online learning barriers and alternatives using moodle/google classroom during covid-19 pandemic. International Journal of Higher Education, 9(6), 1-9.

Okmawati, M. (2020). The use of google classroom during pandemic. Journal of English Language Teaching, 9(2), 439443.

Pratiwi, A. E., \& Trisnawati, N. (2021). Respon siswa terhadap penggunaan google classroom pada mata pelajaran OTK humas dan keprotokolan. Journal of Office Administration: Education and Pratice, 1(1), 28-41.

Pratiwi, S. N., Cari, C., \& Aminah, N. S. (2019). Pembelajaran IPA abad 21 dengan literasi sains siswa. Jurnal Materi dan Pembelajaran Fisika (JMPF), 9(1), 3442.

Ramdhani, M. A., Aulawi, H., Ikhwana, A., \& Mauluddin, Y. (2017). Model of green technology adaptation in small and medium-sized tannery industry. Journal of Engineering and Applied Sciences, 12(4), 954-962.

Shaharanee, I. N. M., Jamil, J. M., \& Rodzi, S. S. M. (2016). The application of google classroom as a tool for teaching and learning. Journal of Telecommunication, Electronic and Computer Engineering, $8(10), 5-8$.

Shahroom, A. A., \& Hussin, N. (2018). Industrial revolution 4.0 and education. International Journal of Academic Research in Business and Social Sciences, 8(9), 314-319.

Syakur, A., Sugirin, S., \& Widiarni, W. 
(2020). The effectiveness of english learning media through google classroom in higher education. Britain International of Linguistics Arts and Education (BIoLAE) Journal, 2(1), 475-483.

Uys, P. M. (2010). Implementing an open source learning management system: A critical analysis of change strategies. Australasian Journal of Educational Technology, 26(7), 980-995.

Wang, Q., Woo, H. L., Quek, C. L., Yang, Y., \& Liu, M. (2012). Using the Facebook group as a learning management system: An exploratory study. British Journal of Educational Technology, 43(3), 428-438.

Watson, W. R., \& Watson, S. L. (2007). An argument for clarity: What are learning management systems, what are they not, and what should they become? TechTrends, 51(2), 28-34.

Webster, J., \& Hackley, P. (1997). Technology-mediated distance learning. Academy of Menagement Journal, 40(6).

Wijaya, C. A., Handhika, J., \& Kartikawati, S. (2017). Pengembangan media pembelajaran pengendali kecepatan dan soft starting motor listrik berbasis arduino pada mata kuliah penggunaan dan pengaturan motor. JUPITER(Jurnal Pendidikan Teknik Elektro), 2(2), 15-20.

Yolandari, A., Meuthia, R. F., \& Fontanella, A. (2020). Penerapan e-learning platform google classroom untuk menjawab tantangan revolusi industri 4 .0 (studi kasus di jurusan akuntansi politeknik negeri padang). Jurnal Akuntansi dan Manajemen, 15(2), 141-155. 